\title{
ANÁLISE DAS PREFERÊNCIAS PROFISSIONAIS DOS FORMANDOS DE ADMINISTRAÇÃO DE EMPRESAS DE UM CENTRO UNIVERSITÁRIO
}

\section{Resumo:}

Planejar a carreira é requisito fundamental para quem almeja o sucesso. Este estudo se propôs a identificar e analisar, através do método de Schein (1978) de inclinações profissionais, as preferências laborais dos fornandos do curso de Administração de Empresas, de um Centro Universitário. Para tanto, apoiou-se no método exploratório, descritivo e quantitativo, sendo o questionário utilizado para a coleta de dados. Constatou-se também que a âncora mais presente nos respondentes foi a de Estilo de Vida e espera-se que esta pesquisa traga contribuições às empresas de modo que reflitam sobre os seus modelos de gestão de pessoas.

Palavras-chave: Planejamento de Carreira. Autoconhecimento. Âncoras de Carreira.

\begin{abstract}
:
Plan career is a fundamental requirement for those who crave success. This study aimed to identify and analyze, through the method Schein (1978) of professional inclinations, labor preferences fornandos's degree in Business Administration, a University Center. Therefore, it relied on exploratory, descriptive and quantitative method, and the questionnaire was used to collect data. It was also found that most respondents in this anchor was the Vid Style and it is hoped that this research bring contributions to companies to reflect on their people management models.
\end{abstract}

Keywords: Career Planning. Self-knowledge. Career anchors.

\footnotetext{
1 Auxiliar Administrativo - Bacharel em Administração de Empresas pelo Centro Universitário UNIVATES. (marywerle@gmail.com)

2 Professora e Coordenadora do curso de Gestão de RH do Centro Universitário UNIVATES. Dotoranda em Psicologia. Ms. Psicologia Social. Esp. Gestão Estratégica de Pessoas. (licidiehl@gmail.com)
} 


\section{INTRODUÇÃO}

O grande fluxo de informações e acontecimentos, que chegam ao conhecimento de todos em tempo real, e as constantes mudanças do mundo globalizado têm exigido, cada vez mais, uma postura proativa das organizações e das pessoas. Sobre mudanças organizacionais, Gil (2009) e Costa (2010) enfatizam que muitas empresas não resistiram à pressão das mudanças de natureza ambiental e organizacional que vêm ocorrendo desde a época de 1980, como a globalização dos mercados, avanços tecnológicos, evolução dos meios de comunicação e competitividade; no entanto, as que conseguiram se adaptar, passaram por processos como a reengenharia, a terceirização e o downsizing, que afetaram significativamente as pessoas envolvidas no sistema.

Administrar a carreira era um trabalho realizado mais pelas empresas do que pelos funcionários. Todavia, tendo em vista a crescente necessidade de adoção de postura proativa por parte das organizações, delegar tarefas e acompanhar resultados não é mais o bastante. Essa mudança na forma de gestão pode ser justificada também pela mudança de comportamento dos funcionários, cujo domínio da carreira passa a ser de sua responsabilidade, em vez de controlada pela empresa (DUTRA, 2011).

A escolha de um curso de graduação pode ser feita por diversos motivos e leva em conta diferentes fatores, como família, sociedade, recursos financeiros, identificação com o curso, interesses pessoais, entre outros (DUTRA, 2011). Então, de um lado estão as pessoas interessadas em encontrar uma carreira profissional que as realizem; do outro, o ambiente cada vez mais dinâmico requer, das organizações, um quadro funcional competente, conferindo relevância ao papel do administrador.

O curso de graduação em Administração do Centro Universitário Univates, alinhado a isso, busca qualificar e capacitar seus alunos para que compreendam "[...] tanto os aspectos técnicos relativos à profissão quanto os aspectos relacionados à gestão de pessoas, fundamental para o atendimento dos objetivos organizacionais" (CENTRO UNIVERSITÁRIO UNIVATES, 2014, texto digital). A abrangência da formação do administrador permite a atuação em diversos tipos de organização e níveis, tanto em cargos técnicos quanto gerenciais, e a proximidade e interação com as empresas, proporcionada pelo curso, geram situação especial ao estudante, permitindo que amplie o contato com a realidade empresarial. O profissional poderá atuar na área pública ou privada, com opções de atividades que podem ser desenvolvidas nas áreas Financeira, Orçamentária, Administração Estratégica, Administração de Materiais, Produção e Logística, Administração de Vendas e de Marketing, Administração de Recursos Humanos e Administração de Sistemas de Informações (CENTRO UNIVERSITÁRIO UNIVATES, 2014, texto digital).

O planejamento de carreira precisa sair da mente e ser formalmente estruturado. Colocando as ideias no papel, há uma visualização das metas e objetivos a serem alcançados. No Brasil, as pessoas ainda resistem a planejar suas carreiras, como afirma Dutra (2011), de modo que não se dão conta da oportunidade estratégica que estão deixando escapar.

Posto isso, este estudo propõe apresentar e analisar as atividades atuais, expectativas de trabalho e as inclinações de carreira dos formandos 2014/B do curso de Administração da Univates. Para tanto, a pesquisa, de caráter exploratório e descritivo, seguiu delineamento quantitativo, tendo sido utilizado o questionário para a coleta de dados e, para o tratamento de dados, foram utilizadas técnicas estatísticas. A pesquisa foi realizada no Centro Universitário Univates, situado na cidade de Lajeado/RS. O público-alvo da pesquisa foi composto por estudantes do curso de graduação em Administração de Empresas, formandos do segundo semestre de 2014, totalizando 36 respondentes.

A seguir, apresenta-se uma síntese sobre os assuntos de planejamento de carreira, autoconhecimento e âncoras de carreira, seguido da metodologia e resultados do estudo. 


\section{Planejamento de carreira}

Após a Segunda Guerra Mundial, estudiosos de Administração Científica começaram a dar ênfase ao estudo das carreiras de trabalho dentro das organizações devido à complexidade que se instalou dentro das empresas. Nos anos 60, esse quadro se alterou devido à complexidade técnica presente nas empresas, abertura de mercados e a mudanças no estilo de vida das pessoas. Nos anos 70, aparecem os primeiros livros tratando do assunto, e, nos anos 80 , essas discussões e práticas de gestão realmente começaram a ser desenvolvidas. Mas foi nos anos 90 que a discussão de planejamento de carreira foi estruturada (DUTRA, 2011).

O termo carreira é amplo e há inúmeras conceituações, de modo que Dutra (2011, p. 17) considera o conceito de London e Stump mais adequado: "Carreira são as sequências de posições ocupadas e de trabalhos realizados durante a vida de uma pessoa". Envolve uma série de fatores e acontecimentos na vida das pessoas que trazem necessidades, motivações, perspectivas individuais além de imposições organizacionais e da sociedade. $\mathrm{Na}$ conceituação de Oliveira (2009, p.5), "Carreira é o conjunto planejado, estruturado e sustentado de estágios que consolidam a realidade evolutiva de cada indivíduo, de forma interativa com as necessidades das empresas e comunidades onde elas atuam".

A evolução das carreiras, ao longo do tempo, passou de um modelo estável de trabalho e linear, para uma perspectiva horizontalizada, até em forma de espiral, em que o indivíduo precisa buscar se qualificar constantemente e desenvolver competências para se destacar no meio competitivo (TOLFO, 2002). Cada vez mais, vem-se observando que a carreira está sendo considerada responsabilidade de cada um, pois aquela empresa que gerenciava a carreira dos funcionários está se dissolvendo (PASCHOAL, 2004). Em atinência, Robbins (2005) afirma que as carreiras tradicionais lineares eram fruto de um ambiente previsível, e as pessoas também eram submissas e esperavam que seus esforços fossem reconhecidos para ascender dentro da hierarquia empresarial.

Ao se falar em plano de carreira, convém pensar em algo formalmente escrito, como traz Oliveira (2009): um estudo que possa ser melhorado com o passar do tempo, pois uma ideia que está somente em mente não tem como ser aprimorada. Acrescenta Oliveira (2009, p. 4) que "é o documento formal que consolida informações, atividades e decisões desenvolvidas com base em uma metodologia de planejamento de carreira". Ainda nessa perspectiva, Nascimento e Carvalho (2006, p. 163) colocam que planejamento de carreira "é o estudo das metas e da trajetória de carreira dos colaboradores nos diferentes cargos da empresa, enquanto o plano de carreira é a materialização desse estudo, ou seja, o instrumento que estabelece as trajetórias de carreiras existentes na empresa".

A carreira de uma pessoa deve ser tratada de forma individual, considerando o meio em que está inserida e os interesses da empresa, mas cada pessoa deve tomar partido de suas próprias metas e objetivos. Todos têm uma carreira profissional, pois a carreira pode ser definida por sucessões de experiências profissionais ao longo da vida e não está somente ligada a trabalho remunerado, mas também a experiências, como estudos, vivências e até trabalho voluntário (ROBBINS, 2005).

Portanto, a patir das colocações dos autores, o planejamento de carreira é um assunto pertinente à vida profissional de cada indivíduo e de relevância significativa para o cenário atual do mercado de trabalho. Evidencia-se a necessidade de cada pessoa pensar e repensar sua trajetória profissional e traçar um plano para si, com metas e objetivos claros, que possam ser concretizados ou remanejados, acompanhando as mudanças que ocorrem na gestão de pessoas e nos cenários organizacionais. 


\section{Autoconhecimento}

As pessoas precisam ser analisadas individualmente para que se tenha real conhecimento de sua personalidade, de quem realmente são. Osborn, Hunt e Schermerhorn (1998, p.69), sobre a formação da personalidade, referem que "A personalidade é determinada tanto por hereditariedade como pelo ambiente; nas características de personalidade, a proporção é cerca de $50 \%$ hereditariedade e $50 \%$ de ambiente". Chiavenato (2009, p. 118) complementa definindo personalidade como "um conjunto relativamente estável de características individuais e de temperamento, formado por herança e por fatores sociais, culturais e ambientais". 0 autor acrescenta que cada indivíduo é diferente e se adapta melhor a certos ambientes.

Para o conhecimento individual, é necessário reconhecer seus pontos fortes e fracos, através de meios externos, como terapias psicanalíticas, cursos de autoconhecimento, workshops de carreira, livros de autoajuda, coaching pessoal (COSTA, 2010). Pontos fortes, para Oliveira (2008, p. 71), são "diferenciações controláveis conseguidas pelas pessoas, de forma planejada e controlada, e que lhes proporcionam vantagens competitivas em relação aos outros", e pontos fracos "são situações controláveis, mas inadequadas, que as pessoas apresentam e que lhes proporcionam desvantagens competitivas em relação aos outros".

$\mathrm{Na}$ busca por autoconhecimento, o indivíduo deve ter claro, para si, sua missão, seus valores e sua visão, pois é a partir desses princípios que seu caminho será trilhado. Assim, Borba (2011, p. 90) coloca essa interação de princípios da seguinte forma:

- Missão: Por que existimos? Onde estamos? = Identidade

- Visão: Para onde vamos? Qual é o nosso destino? = Destino

- Valores: Que crenças orientarão o nosso comportamento? = Crença

- Estratégia: Como seremos diferentes ao criar valor? = Caminho

Ao fazer parte de uma organização, cada pessoa leva suas características pessoais para somar com as características do grupo que fará parte. Para Blanco (2010), está havendo uma crise nos valores, consequente dos novos tempos, por isso a necessidade de pessoas que trazem consigo valores e crenças que realmente possam somar às organizações, sabendo o que realmente querem, por que fazem (missão) e que sejam visionárias, no sentido de conseguirem visualizar cenários futuros para si e para o mercado competitivo. Complementa Robbins (2011) que o indivíduo, ao entrar em uma empresa, traz consigo um conjunto de valores e atitudes e uma personalidade estabelecida. Embora não exerçam impacto direto sobre o comportamento, os valores influenciam as atitudes do indivíduo.

Portanto, o conhecimento do sistema de valores de alguém ajuda no entendimento de suas atitudes, pois pessoas que têm valores concordantes com os organizacionais tendem a ser mais satisfeitas em relação ao trabalho. Dessa forma, é importante, no planejamento de carreira, criar critérios para encontrar organizações que têm valores compatíveis com os pessoais.

\section{Âncoras de carreira}

As pessoas ainda são muito resistentes e as empresas pouco estimulam seus colaboradores a planejarem suas carreiras. Dutra (2011, p. 23) comenta que "a maioria das pessoas encara a reflexão sobre suas carreiras apenas como a identificação de oportunidades e a busca de seu aproveitamento". Dessa forma, tornam-se coadjuvantes da própria história e perdem a chance de atuar nesse contexto no sentido de verificar oportunidades, novos meios de levar 
suas vidas profissionais, adequando suas preferências pessoais aos valores organizacionais.

Dutra (2011) aponta que Edgar Schein (1978) fez um estudo com 44 alunos da Sloan School of Management do MIT (Massachusetts Institute of Technology), no período de 1961 a 1973, classificando oito categorias de âncoras de carreira que são: competência gerencial; competência técnica-funcional; segurança e estabilidade; autonomia e independência; criatividade empreendedora; senso de serviço e dedicação à causa; desafio constante; e estilo de vida integrado. Essas categorias, descritas por Schein (1978 e 1990) e apresentadas por Dutra (2011), são detalhadas a seguir:

\section{- Competência gerencial: Âncora 1}

As pessoas que fazem parte dessa categoria destacam-se em atividades que tem por objetivo final funções de gerenciamento. Destacam-se características analíticas (capacidade de identificar e solucionar problemas mesmo em condições de incerteza); competência interpessoal (habilidade de persuadir pessoas, a fim de atingir objetivos organizacionais); estabilidade emocional (sentir-se estimulado mesmo sob pressão, resistir a momentos de crise e saber fazer uso da autoridade).

- Competência técnica-funcional: Âncora 2

As pessoas classificadas nessa âncora são muito eficientes em sua área técnica, exercendo, com excelência, as funções específicas para a qual estão qualificadas. Não estão interessadas em posições gerenciais, a não ser que seja para a função que lhes compete. Podem ser consultoras externas de sua área específica também.

\section{- Segurança e estabilidade: Âncora 3}

Os profissionais que têm inclinações para essa âncora procuram estabilidade e segurança, empresas que oferecem benefícios, além de salários. Querem se sentir seguros e esperam que a empresa conduza da melhor forma suas carreiras profissionais, assim como também esperam dela reconhecimento pelo esforço despendido, seja a área que for. São exemplos dessa âncora as pessoas que exercem função no serviço público. São pessoas que buscam estabilidade e rotina.

\section{- Criatividade empreendedora: Âncora 4}

O empreendedorismo é característica relevante dessa âncora, por isso as pessoas dessa categoria se destacam por querer algo mais, algo que seja a própria extensão de si próprias, como um produto ou serviço. Tentam se destacar em suas atividades mesmo quando funcionárias de uma empresa, cunhando meios de criar, ou então buscam a satisfação de seus anseios, por meio de hobbies ou atividades diferentes do seu trabalho. Imaginam ter sucesso a partir do acúmulo financeiro.

\section{- Autonomia e independência: Âncora 5}

Esse grupo de pessoas tenta aumentar suas chances de exercer autonomia dentro das organizações onde estão inseridas, prezam a liberdade e se preocupam em manter seu ritmo de trabalho, suas prioridades e hábitos. Tendem a procurar profissões que lhes permitam essa "liberdade" de exercer o trabalho ao seu modo.

- Senso de serviço e dedicação à causa: Âncora 6

Fazem parte, dessa categoria, pessoas que procuram não somente uma profissão, mas também fazer um bem ao próximo, à sociedade. São leais aos seus valores e da organização, esperam uma remuneração justa pelo que fazem, mas não é o seu foco principal. Podem ser exemplos dessa âncora: médicos, enfermeiros, assistentes sociais, ambientalistas, religiosos, etc. 


\section{- Desafio constante: Âncora 7}

As pessoas dessa categoria são movidas pelo desafio, são altamente competitivas e gostam de se sentir em risco. Sem esse requisito, o trabalho fica tedioso e sem motivação. Os "casos perdidos", para as pessoas que fazem parte dessa âncora, por exemplo, são um estímulo para o trabalho. Segundo Marques e Carli (2012), essas pessoas são movidas pelo desafio e veem, na dificuldade, uma alternativa de resgate e sucesso, são desafiadoras de si mesmas.

\section{- Estilo de vida integrado: Âncora 8}

As pessoas que fazem parte dessa âncora se caracterizam por quererem integrar as necessidades individuais, familiares e da carreira. Não se trata de equilíbrio entre, mas, sim, a possibilidade de tratar os assuntos com a mesma prioridade. Procuram flexibilidade no emprego.

Apresentados os principais entendimentos dos autores acerca de planejamento de carreira, autoconhecimento e âncoras de carreira, serão apresentados, na sequência, os procedimentos metodológicos adotados para atingir-se o objetivo da pesquisa.

\section{Método de pesquisa}

Trata-se de uma pesquisa de natureza exploratória e descritiva, de abordagem quantitativa, por meio da qual se buscou identificar e analisar, através do método de Schein (1978) de inclinações profissionais, as preferências profissionais dos sujeitos de pesquisa, bem como as suas atividades atuais de trabalho.

A fase exploratória da pesquisa buscou investigar os assuntos relacionados ao tema do trabalho em pesquisas bibliográficas à disposição. A importância de referenciar os assuntos pesquisados justifica-se por simplificar a associação dos dados levantados na fase quantitativa da pesquisa com os dados obtidos nos questionários. Segundo Malhotra (2004, p. 99), "A pesquisa exploratória é usada em casos nos quais é necessário definir o problema com maior precisão, identificar cursos relevantes de ação ou obter dados adicionais antes de poder desenvolver uma abordagem".

A etapa descritiva quantitativa do trabalho foi a mais importante, uma vez que, com os dados obtidos através do questionário, foi possível tratar por meios estatísticos o problema de estudo e atingir os objetivos do trabalho, sendo possível a identificação da âncora de carreira de cada respondente. Para Gil (2007), a pesquisa descritiva visa descrever as características de determinada população, uma situação, fato ou alguma coisa. As informações, obtidas por meio do questionário, foram tabuladas, colocadas em porcentagem e apresentadas de forma gráfica, facilitando a sua compreesão.

Como técnica de coleta de dados, optou-se por questionário composto por Bloco A, que contemplou os dados sociodemográficos para verificar o perfil dos respondentes e questões relativas às suas atividades profissionais, como tempo de atuação na empresa, se atua na área da administração, em que área específica dessa atua, área que gostaria de atuar e fatores motivadores de escolha pelo curso de Administração. Além disso, o Bloco A conteve duas questões abertas que permitiram a expressão escrita e livre do respondente.

O Bloco B, por sua vez, foi elaborado a partir do método de Schein para identificação das âncoras de carreira dos respondentes, por meio do qual se obteve os resultados para cada categoria de âncora, que poderiam ser: competência gerencial; competência técnica-funcional; segurança e estabilidade; autonomia e independência; criatividade empreendedora; senso de serviço e dedicação à causa; desafio constante; e estilo de vida integrado.

O questionário é um dos meios mais eficazes para se obter dados em pesquisas quantitativas 
nas áreas de ciências sociais e deve ser adequado ao público-alvo em termos de linguagem compreensível e nível intelectual (BOTELHO; ZOUAIN, 2009). Os autores complementam que (p. 90) "precisa, portanto, ser bem elaborado, pois proporciona padronização e uniformização no processo de coleta de dados, facilitando posteriormente a análise de dados [...]". Ainda, o objetivo principal do questionário é levantar dados consideráveis para responder ao problema de pesquisa, por isso sua necessidade de clareza nas questões e de respostas precisas.

Para que o estudo se efetive, é preciso selecionar sujeitos. Isso é requisito fundamental, uma vez que a pesquisa tem como objetivo generalizar os resultados, referindo-se aos sujeitos que fazem parte da amostra selecionada, então, no caso, o sujeito da pesquisa é todo o participante da amostra (GIL, 2007). Os sujeitos desta pesquisa foram os formandos do curso de Administração de Empresas 2014/B do Centro Universitário Univates, situado em Lajeado/ RS. A população-alvo envolveu a totalidade destes formandos, de modo que foram enviados 72 questionários por e-mail, retornando 36 , sendo estes considerados neste estudo.

Devido à pesquisa ser não probabilística, portanto não conclusiva, terá validade somente para o presente trabalho. "Os levantamentos abrangem um universo de elementos tão grande que se torna impossível considerá-los em sua totalidade. Por essa razão, o mais frequente é trabalhar com uma amostra" (GIL, 2007, p. 121).

A supervisão aos pesquisadores para que erros sejam evitados durante a coleta de dado, conforme Gil (2007), é essencial. É preciso que os pesquisadores sejam confiáveis, éticos e não coletem dados de qualquer jeito. A coleta de dados foi realizada pela pesquisadora responsável pela pesquisa, a qual se comprometeu com a ética e a correta apresentação dos dados obtidos. Os e-mails dos formandos 2014/B, para os quais foram enviados os questionários, foram de acesso da pesquisadora por esta fazer parte dessa turma de formandos do semestre 2014/B de Administração de Empresas do Centro Universitário Univates.

Após o prazo estabelecido para retorno do questionário, ocorreu a interpretação dos dados, que consiste em estabelecer uma ligação entre os resultados e as teorias apresentadas anteriormente na fase exploratória. "O processo de análise de dados envolve diversos procedimentos: codificação das respostas, tabulação dos dados e cálculos estatísticos" (GIL, 2007, p. 125).

Planejar essa fase de análise e apresentação de dados é interessante, como aborda Lakatos e Marconi (2010), para que sejam destacadas apenas as tabelas e informações necessárias às respostas ao objetivo do projeto, tornando-as, assim, compreensível. Em vista disso, os dados obtidos por meio do questionário foram tabulados e convertidos em porcentagens, dando-se evidência aos dados que mais se destacam e aos que menos se destacam no perfil dos respondentes. A análise pelo percentual mais e menos evidente também foi feita em relação aos resultados correspondentes às atividades profissionais e ao objetivo de identificar e analisar as âncoras de carreira. Já as respostas às perguntas abertas foram analisadas buscando entender as motivações e justificativas dos respondentes para situações de suas carreiras atuais.

Toda pesquisa e método têm possibilidade de limitações, mas nada que impeça sua realização, segundo Gil (2007). No caso do presente trabalho, a pesquisa só é válida para os formandos de Administração 2014/B do Centro Universitário Univates, não se estendendo às demais universidades, nem estudantes. Os participantes do estudo foram eleitos por motivo de proximidade e conveniência. 


\section{Análise e interpretação de dados}

Em relação aos dados do perfil dos formandos de Administração 2014/B do Centro Universitário Univates que participaram do estudo, dos 36 respondentes, 25 pessoas são do sexo feminino, equivalendo a $69 \%$; e 11 pessoas são do sexo masculino, no caso, $31 \%$. A faixa etária dos participantes variou, conforme Tabela 1.

Tabela 1 - Faixa etária dos respondentes da pesquisa

\begin{tabular}{|c|c|c|}
\hline Faixa etária & Respondentes & Percentual \\
\hline 18 a 25 anos & 7 & $19 \%$ \\
\hline 26 a 30 anos & 21 & $58 \%$ \\
\hline 31 a 35 anos & 2 & $6 \%$ \\
\hline 36 a 40 anos & 4 & $11 \%$ \\
\hline 41 a 50 anos & 2 & $6 \%$ \\
\hline Total & 36 & $100 \%$ \\
\hline
\end{tabular}

Fonte: Dados primários obtidos através de questionário.

Percebe-se que 58\% dos respondentes estão na faixa de 26 a 30 anos. Para Dutra (2011), essa é uma fase de estabelecimento, em que geralmente o indivíduo se encontra profissionalmente, e de possíveis mudanças, para que se estabeleça no universo do trabalho. Formar-se, nessa fase, pode somar à decisão por determinada carreira ou promover uma mudança positiva na vida pessoal, o que varia com os objetivos de cada pessoa.

Quanto ao estado civil, a maioria dos respondentes é solteiro (55\%) e $25 \%$ são casados. A opção "outro" foi escolhida por $17 \%$. Atualmente, muitas pessoas optam por primeiro estabelecer sua vida profissional e posteriormente oficializar seus relacionamentos. Ainda, para Marques e Carli (2012), o importante, é estar ao lado de pessoas que somem à vida pessoal e que estimulem a carreira profissional, participando alegremente das conquistas. A postergação da oficialização das relações pode ser devido a certos contratempos que envolvem vida pessoal e profissional, pois há uma dificuldade de equilibrar esses setores da vida para algumas pessoas, daí a escolha de se estabelecer profissionalmente em primeiro lugar (BORGES; MIRANDA; CASADO, 2011).

No que se refere ao tempo de empresa, é possível constatar que a maioria (56\%) possui entre dois e dez anos de estabilidade no local onde atuam, enquanto $25 \%$ têm até dois anos de atuação na mesma empresa, como pode ser observado na Tabela 2:

Tabela 2 - Tempo de empresa

\begin{tabular}{|c|c|c|}
\hline Tempo de empresa & Respondentes & Percentual \\
\hline Menos de 1 ano & 3 & $8 \%$ \\
\hline De 1 a 2 anos & 6 & $17 \%$ \\
\hline De 2 a 5 anos & 12 & $34 \%$ \\
\hline De 5 a 10 anos & 8 & $22 \%$ \\
\hline De 10 a 15 anos & 4 & $11 \%$ \\
\hline Acima de 15 anos & 3 & $8 \%$ \\
\hline Total & 36 & $100 \%$ \\
\hline
\end{tabular}

Fonte: Dados primários obtidos através de questionário. 


\section{PUC-SP}

Um ponto relevante, para aqueles que estão há muitos anos na mesma empresa (que não são a maioria nesta pesquisa), é cuidar para não cair na zona de conforto da carreira, sendo indicado rever, periodicamente, se a carreira está de acordo com os objetivos pessoais pretendidos. A esse respeito, Chiavenato (2006) coloca que a carreira deve ser repensada de tempos em tempos, verificando se os objetivos profissionais de crescimento estão sendo atingidos dentro da empresa, pois, para casos de estagnação na carreira, as soluções podem ser remanejo de cargo dentro da empresa ou até mudança de emprego. Para Passos e Najjar (1999), caindo na zona de conforto da carreira, a pessoa pode ficar sujeita às mudanças do meio, deixando de ser protagonista da própria carreira. Ao tomar uma decisão, como, por exemplo, mudar de emprego, deve-se avaliar cuidadosamente para não acarretar problemas em outros setores da vida pessoal, por isso a importância do planejamento de carreira..

Ter oportunidade de atuar na área em que se estuda, é importante para o profissional adquirir experiência prática ao mesmo tempo em que adquire conhecimentos na universidade. Por isso, os estágios curriculares, além de outros remunerados, são uma alternativa profícua para os estudantes. Dos formandos em Administração 2014/B, 89\% atuam na área de administração, enquanto $11 \%$, não atuam. Desses $11 \%$, os motivos apresentados pelos respondentes estão relacionados ao fato de trabalharem no setor público, atuarem na área de sua formação técnica e entenderem que a área da administração não dispõe de oportunidades atrativas financeiramente.

As áreas em que estão distribuídos os $89 \%$ de respondentes que atuam na área da administração podem ser visualizadas e mensuradas no Gráfico 1.

Gráfico 1 - Área da administração em que atua

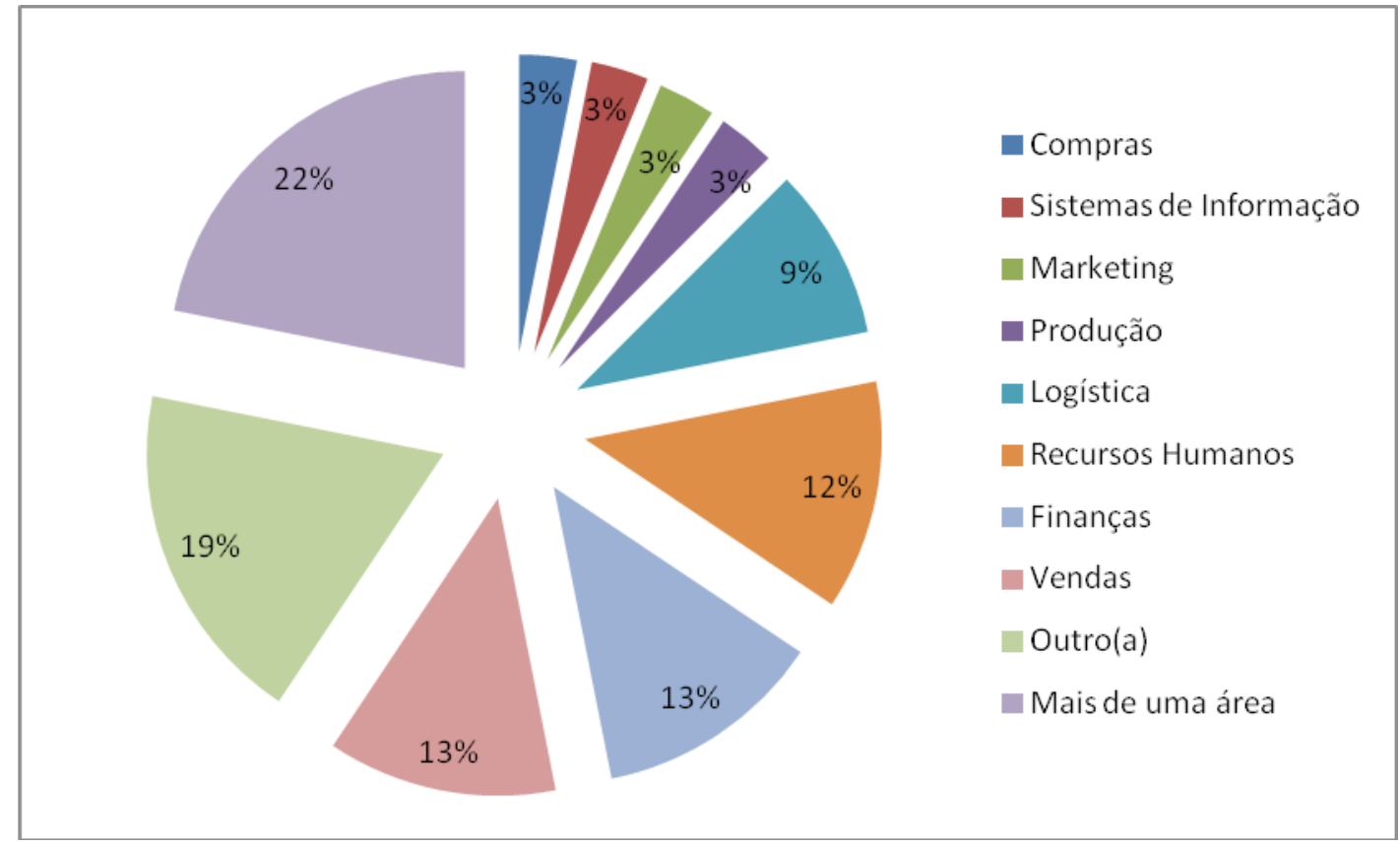

Fonte: Dados primários obtidos através do questionário aplicado.

Os pontos do gráfico que mais se destacaram foram "Mais de uma área" e "Outro(a)". Pode ser observado que $22 \%$ dos respondentes exercem mais de uma função dentro das organizações, o que vem ao encontro do entendimento de Chiavenato (2000) ao afirmar que uma realidade presente dentro de certas estruturas organizacionais, principalmente micro e 
pequenas empresas que têm equipes enxutas, faz com que os funcionários exerçam mais de uma função. Acrescenta-se que o curso de Administração de Empresas da Univates prepara o aluno para que esteja apto a atuar em diversas áreas, o que possibilita que ele possa escolher não só uma atividade e desenvolvê-la, mas também aprender um pouco de cada área (CENTRO UNIVERSITÁRIO UNIVATES, 2014, texto digital).

$\mathrm{Na}$ área "outro(a)", que representa 19\%, foi solicitado que o respondente especificasse qual a sua atividade. As respostas obtidas foram: responsável pelas operações do sistema elétrico da empresa; gerente; administrador de empresa familiar; caixa em agência bancária; gestor. Essas informações mostram que a maioria dos respondentes está atuando em uma atividade relacionada ao curso de formação e correspondem a um dos objetivos do curso de Administração da Univates, que é formar profissionais com capacidade de tomada de decisão, condução de pessoas por meio da liderança, resolução de problemas e, principalmente, desenvolver o espírito empreendedor (CENTRO UNIVERSITÁRIO UNIVATES, 2014, texto digital).

As áreas que mais interessam aos formandos 2014/B que participaram da pesquisa podem ser verificadas no Gráfico 2.

Gráfico 2 - Área de maior interesse de atuação

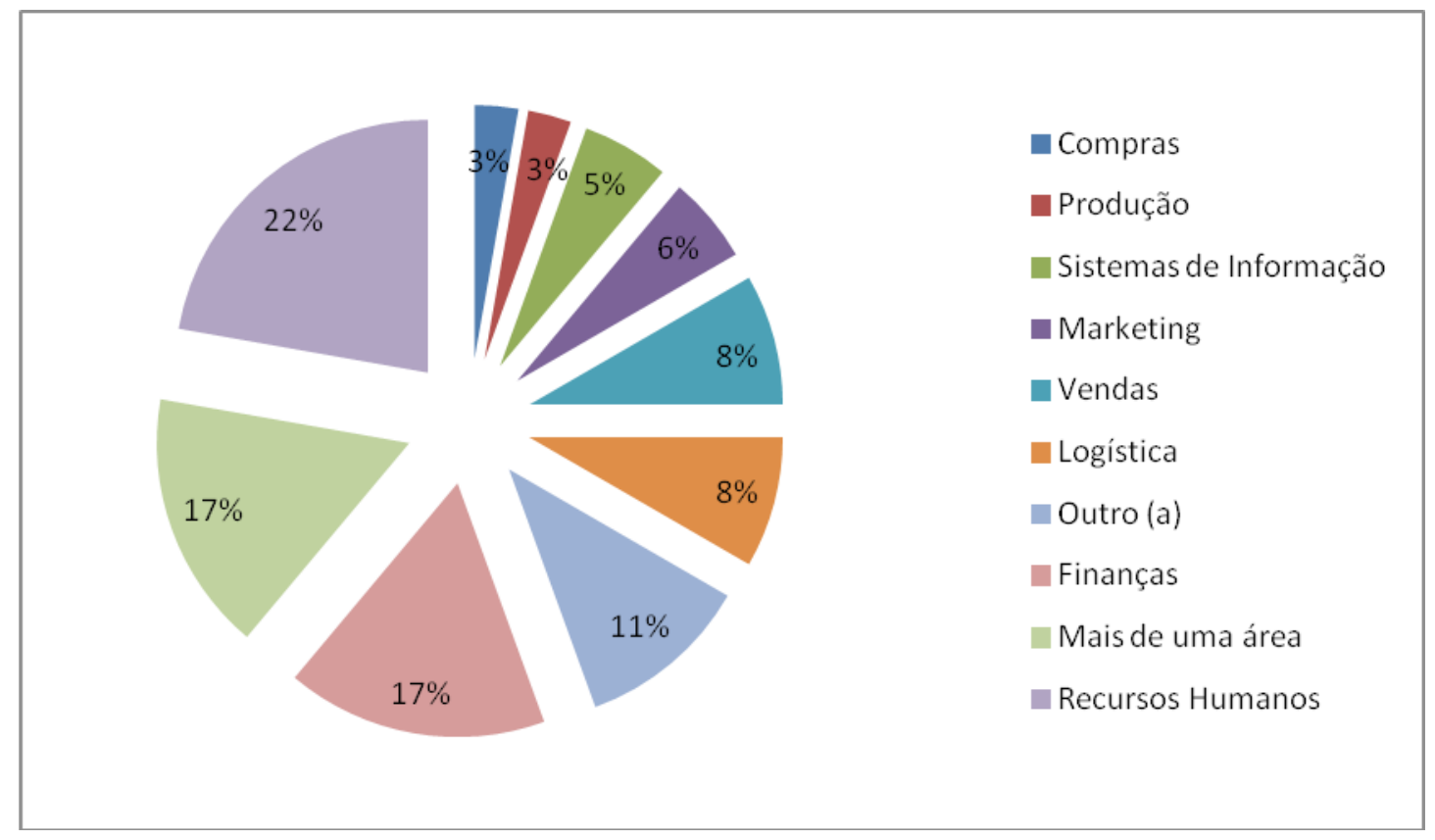

Fonte: Dados primários obtidos através do questionário aplicado.

A área de Recursos Humanos foi apontada como sendo a área de maior interesse dos respondentes ( $22 \%$ de escolha), seguida das áreas de Finanças e Mais de uma área (ambas escolhidas por $17 \%$ dos respondentes). As opções Vendas e Logística tiveram o mesmo resultado ( $8 \%$ cada), seguida da área de Marketing (6\% dos respondentes) e Sistemas de Informação ( $5 \%$ de escolha). Considerando a área de interesse apontada, percebe-se que houve aumento significativo nas áreas de Recursos Humanos, Marketing e Sistemas de Informação, em comparação ao gráfico 1, que apresenta as atividades atuais de trabalho. Isso se deve, possivelmente, pelo amplo campo da área da administração (CENTRO UNIVERSITÁRIO UNIVATES, 2014, texto digital), oferecendo oportunidade para o profissional experienciar uma área e se identificar ou não com ela, possibilitando a busca de outras opções. 
Visto o fato de terem clareza sobre seus interesses, seria viável traçar um plano de ação a partir de ferramentas propícias para tal, como, por exemplo, o $5 \mathrm{~W} 1 \mathrm{H}$ (What, Who, Where, When, Why and How) 1 dentro do seu planejamento de carreira, para chegar aos seus objetivos (CHIAVENATO, 2006; DUTRA, 2011; OLIVEIRA, 2009). Os autores afirmam que o planejamento de carreira deve partir do autoconhecimento e processo de autoavaliação pessoal, seguido de análise de cenários, identificação de oportunidades e, para implementação, um plano de ação. O planejamento deve conter todos esses itens, pois as etapas são interativas, não havendo previsão do surgimento de oportunidades, mas devendo a pessoa estar preparada antecipadamente para reconhecê-las.

Há diversos motivos para uma pessoa escolher uma carreira, sendo o curso de graduação um componente relevante na carreira de uma pessoa, pois ele vai direcionando os interesses de cada um. Xavier (2006, p. 74) diz que decisões eficientes no âmbito da carreira "levam em conta efetivamente os valores pessoais, o perfil emocional da pessoa, e não apenas vantagens ou benefícios econômicos". No caso, para os respondentes da pesquisa, os principais fatores motivadores para a escolha do curso foram os apresentados na Tabela 3:

Tabela 3 - Fatores de escolha do curso de Administração

\begin{tabular}{|c|c|c|}
\hline Fator motivador & & \\
\hline Incentivo Familiar & 2 & $6 \%$ \\
\hline Vocação & 2 & $6 \%$ \\
\hline Outro Motivo & 3 & $7 \%$ \\
\hline Atuava na Área & 4 & $11 \%$ \\
\hline Almeja ter Negócio Próprio & 5 & $14 \%$ \\
\hline Maior disponibilidade de Emprego & 20 & $56 \%$ \\
\hline Total & 36 & $100 \%$ \\
\hline
\end{tabular}

Fonte: Dados primários obtidos através do questionário aplicado.

$\mathrm{Na}$ tabela, $56 \%$ dos respondentes revelam a escolha ter sido motivada pela maior disponibilidade de emprego, o que indica tendência de os formandos 2014/B considerarem importante sentirem-se seguros quanto à carreira profissional. A administração tem um campo de atuação amplo, portanto tem mais opções de trabalho para as pessoas que optam por essa graduação. Estar formado em Administração aumenta a empregabilidade da pessoa, trazendo uma vantagem competitiva para seu planejamento de carreira frente ao mercado de trabalho; mas, como nas demais graduações, cabe a cada um buscar as oportunidades, pois apenas estar formado na área sem desenvolver um planejamento pessoal não fornece garantias (OLIVEIRA, 2009).

A partir do teste de âncoras de Schein, foi possível identificar as inclinações profissionais dos respondentes da pesquisa. Neste momento, em que estão em fase final de curso, é interessante trazer esses dados que envolvem as avaliações do passado, presente e futuro profissional, para uma possível reflexão de carreira.

As âncoras que mais se destacam são "Estilo de vida", com 36\%, e "Segurança e estabilidade", com 25\%. Na sequência, aparecem a "Criatividade empreendedora", com 14\%, e "Desafio puro", com 11\%. Destaca-se que a âncora "Competência gerencial" não correspondeu ao perfil do público investigado. Os resultados são confirmados no Gráfico 3.

${ }_{1}$ What (Que/Qual), Who (Quem), Where (Onde), When (Quando), Why (Por que) e How (Como). 


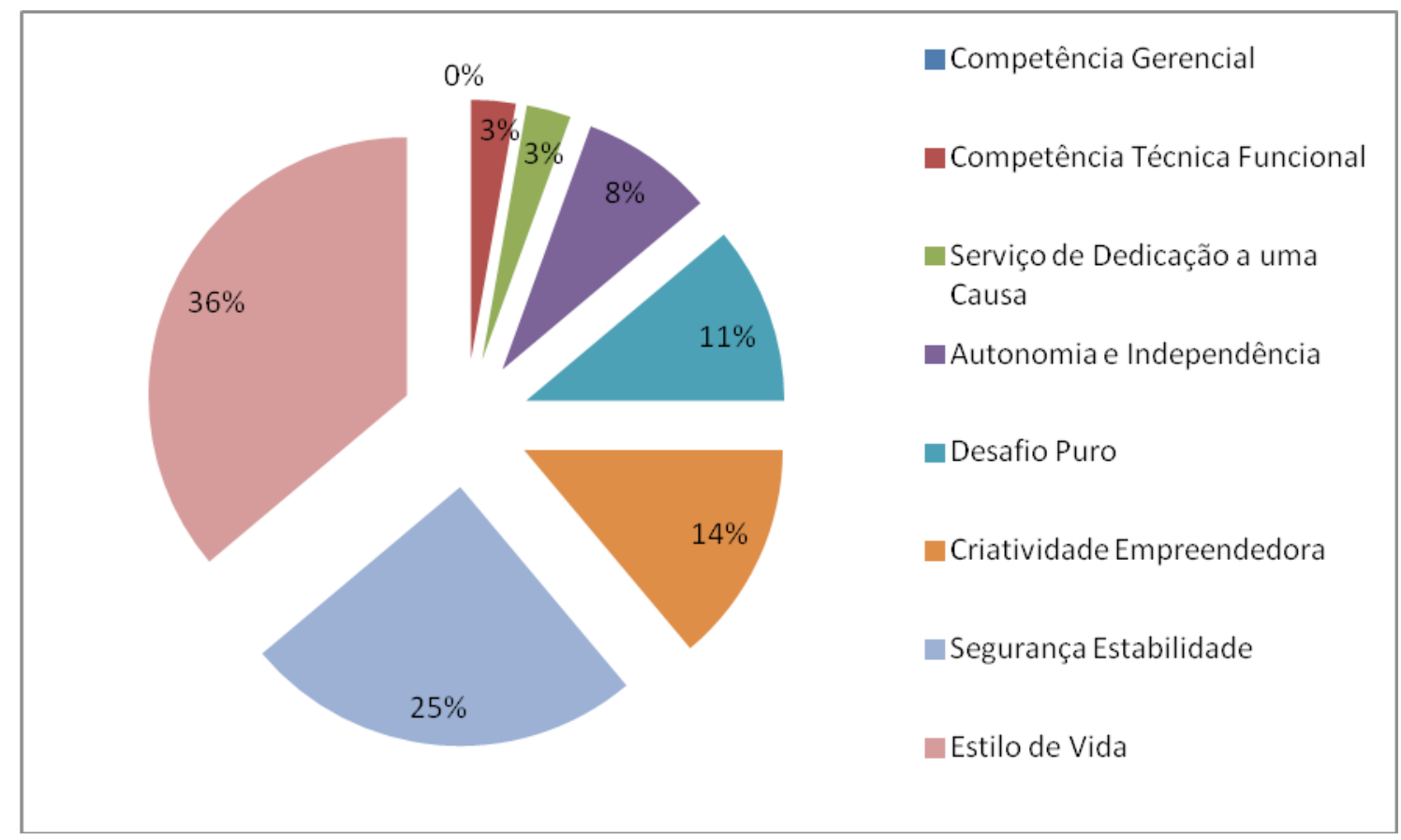

Fonte: Dados primários obtidos através do questionário aplicado.

Um dos fatores que caracteriza a âncora "Estilo de vida" é a necessidade de integrar família, interesses pessoais e trabalho (BORGES; MIRANDA; CASADO, 2011). Por isso, a busca por trabalhos que trazem a possibilidade de conciliar carreira e aspectos pessoais, melhorando a qualidade de vida, é uma tendência nos tempos atuais.

Pode-se destacar, nessa âncora, a relação com o perfil da geraçãoY2, público-alvo da pesquisa. Oliveira (2010) menciona um estudo realizado pela Cia de Talentos-Empresa dos Sonhos em 2009, realizada com mais de 29 mil jovens na América Latina, sendo que o resultado da pesquisa demonstra o que é determinante para esses jovens no momento de escolher uma empresa para trabalhar:

- Um dos principais motivos para escolher uma empresa na qual trabalhar é um ambiente agradável, que não intimida, mas promove o bem estar e o respeito, no qual o trabalho é quase um lazer com constante movimento criativo e um bom relacionamento com os colegas (OLIVEIRA, 2010, p. 66).

Conforme resultado da pesquisa, pode-se constatar que esses jovens não buscam somente por resultado financeiro, procuram também um bom ambiente de trabalho no qual recebam feedback constante de seu desempenho e consigam visualizar possibilidade de crescimento. Pessoas com essa âncora podem encontrar possibilidades consideráveis no curso de Administração, desde empregos, em que já estejam atuando com novas propostas de gestão de pessoas, ou seja, que permitam certas flexibilidades, até o desenvolvimento de negócios próprios.

"Segurança e estabilidade" foi escolhida por $25 \%$ dos respondentes. Esse índice pode

${ }^{2}$ Para Oliveira (2009) apud Sá (2011), a geração Y abrange os jovens nascidos entre os anos de 1980 e 2001. Lancaster e Stillman (2011) referem que a primeira leva da geração Y nasceu entre 1982 e 2000 e passou a ingressar no mercado de trabalho com empregos de meio período a partir de 1990. 
estar relacionado ao indicador "Tempo de empresa" que revelou a maioria (56\%) possuir entre dois e dez anos de estabilidade. Ainda pode ter relação com o indicador "Fatores de escolha do curso de Administração", que demonstrou que 56\% escolheram o curso motivados pela maior disponibilidade de emprego. Para Chiavenato (2006), tanto empresas quanto funcionários podem cair na zona de conforto, o que significa para o funcionário se estagnar na carreira e, para a empresa, manter esquemas retrógrados de gestão de pessoas. No mercado atual de trabalho, manter a mesma função e as mesmas atividades sem nenhuma alteração durante anos significa estagnação de carreira, ou seja, desatualização com as novas concepções de gestão de pessoas.

Por outro lado, o curso de Administração pode representar, para os respondentes identificados nessa âncora, uma possibilidade de concretização de seus intuitos de segurança e estabilidade, uma vez que o curso oferece um amplo campo de atuação, aumenta a empregabilidade, além de proporcionar oportunidades na vida pública e privada. Cabe ressaltar que não se pode instituir formas de condução de carreira. Nesse quesito, cabe, a cada pessoa, saber o que é de seu interesse, no caso, para alguns, a segurança e estabilidade são fatores tidos como prioridade e se sentem motivados nessa condição. Nesse sentido, estariam corretos em segui-los, pois estariam sendo fiéis aos seus objetivos e valores, ao contrário dos que permanecem na zona de conforto, no autoengano (XAVIER, 2006).

A âncora "Criatividade empreendedora" foi resultado de $14 \%$ das respostas dos participantes da pesquisa. A questão do empreendedorismo é muito trabalhada na graduação de Administração, a fim de desenvolver o espírito empreendedor nos alunos. O curso de Administração enfatiza que as atividades empreendedoras não se referem especificamente à abertura de novos negócios, mas também a criatividade e pró-atividade dentro das organizações das quais as pessoas fazem parte (CENTRO UNIVERSITÁRIO UNIVATES, 2014, texto digital). Em casos de não terem espaço para se desenvolver, as pessoas dessa âncora tendem a buscar a realização através de hobbies ou atividades desvinculadas ao trabalho (DUTRA, 2011).

Ressalta-se que, apesar de se encontrar em terceiro lugar, $14 \%$ não é um índice representativo, considerando o resultado geral. Portanto, apesar de as atividades empreendedoras serem estimuladas durante a graduação de Administração, verifica-se que esse perfil tende a não corresponder ao do público-alvo desta pesquisa, o que é coerente aos índices mais elevados de "Estilo de vida" e "Segurança e estabilidade", apresentados e analisados anteriormente.

Seguindo esse raciocínio, está a âncora de carreira "Desafio puro", que foi escolhida por $11 \%$ dos respondentes. Nesse perfil, Marques e Carli (2012, p. 154) afirmam que "a novidade e variedade tornam-se um fim em si e se alguma coisa é fácil, imediatamente, torna-se monótona". Nesse sentido, a possibilidade de a pessoa que exerce mais de um atividade se sentir mais motivada em relação ao seu trabalho é maior que as demais, devido à variedade de atividades e desvio da rotina. Em relação ao curso de Administração, os profissionais têm mais chances de encontrar satisfação em cargos que instiguem esse espírito desafiador e competitivo, ou ainda de almejar o desafio de ter um negócio próprio.

Todavia, parece que não é isso que ocorre com o perfil dos respondentes, uma vez que não está em atinência aos resultados mostrados "Estilo de vida" e "Segurança e estabilidade", com $61 \%$ no total, "Desafio Puro", com 11\% e, para completar, a âncora "Competência gerencial" que não se apresentou como perfil para o grupo de formandos 2014/B. A "Competência gerencial" se caracteriza por pessoas ambiciosas e que aspiram altos cargos dentro das organizações, são líderes e têm poder de persuasão sobre as pessoas. São pessoas com alto controle emocional e suportam bem ambientes com pressão, como colocado pelos autores Dutra (2011) e Marques e Carli (2012). A "Competência gerencial” requer que a pessoa esteja 
sempre atenta para capitalizar oportunidades de maior desafio, com maior abrangência de responsabilidades. Poder integrar esforços de trabalho com um número maior de pessoas e ser responsável por um resultado mais significativo, que empregue um volume maior de recursos a serem administrados, são, para ela, fatores de avaliação de progresso e, portanto, metas de carreira (DUTRA, 2011).

As âncoras de carreira não definem perfis, mas apresentam inclinações profissionais às quais as pessoas mais se assemelham, a partir de suas próprias respostas baseadas em vivências profissionais passadas, presente e perspectivas de futuro. Escolher uma carreira não é simples para alguns, apesar de tão cobrado por familiares e pelo meio social em que se vive. Por isso, os meios de autoconhecimento estão sendo tão difundidos, estimulando as pessoas a planejarem suas carreiras e buscarem sua realização profissional.

\section{Conclusão}

A proposta de planejar a carreira, a partir das contibuições teóricas sobre o assunto tão pertinentes na atualidade, não visa impor uma condição obrigatória, e sim apresentar uma oportunidade para todas as pessoas que estejam interessadas em um desenvolvimento profissional pleno. Este estudo propôs apresentar as atividades atuais, expectativas de trabalho e as inclinações de carreira dos formandos 2014/B do curso de Administração da Univates, tendo como base o método de Schein para identificação das âncoras de carreira.

Quanto às atividades atuais, verificou-se que, do total dos respondentes da pesquisa, $89 \%$ está inserido na área da administração, distribuídos nas diversas áreas que o curso abrange. Esse fator é relevante, pois denota que os estudantes estão identificados com sua escolha de formação. Estar atuando na área da graduação escolhida traz experiências significativas ao currículo profissional do aluno.

As âncoras de carreira apontaram para as inclinações Estilo de Vida, Segurança/ Establidade e Criatividade Empreendedora, como sendo as três mais destacadas. Os modelos de gestão vêm mudando, assim como as pessoas que estão compondo o mercado de trabalho, por isso a busca por ambientes de trabalho mais flexíveis e que possam trazer mais equilíbrio entre vida pessoal e profissional, assim como encontrar a estabilidade desejada ou até ter oportunidade de desenvolver atividades empreendedoras dentro da organização da qual se faz parte.

Espera-se que esta pesquisa seja um estímulo aos estudantes de Administração e outras áreas a buscarem o autoconhecimento e a autonomia sobre os seus planejamentos de carreira profissional e que traga contribuições às empresas de modo que reflitam sobre os seus modelos de gestão de pessoas, podendo conciliar expectativas pessoais e necessidades organizacionais. Assim, no âmbito das organizações, sugere-se a possibilidade de aplicar o método de Schein em processos seletivos internos, alinhando as preferências profissionais dos funcionários com oportunidades de crescimento e promoção. Reitera-se que, quanto mais coerência entre os valores dos funcionários e da empresa, maior a possibilidade de comprometimento e satisfação na carreira por parte dos funcionários e, consequentemente, maior vantagem competitiva para a empresa.

\section{REFERÊNCIAS}

BLANCO, Roberto Álvarez del. Você marca pessoal. São Paulo: Saraiva, 2010.

BORBA, Valdir Ribeiro. Espiritualidade na gestão empresarial: Como ser feliz no trabalho. Rio de Janeiro: Qualitymark, 2011.

BORGES, Jacquelaine Florindo; MIRANDA, Betina Silvestrini; CASADO, Tania. 
Desenvolvimento da carreira: trabalho, família e outras dimensões do projeto de vida da pessoa. In: DUTRA, Joel Souza. Gestão de careiras na empresa contemporânea. São Paulo: Atlas, 2010, p.172-194.

BOTELHO, Delane; ZOUAIN, Deborah Moraes. Pesquisa quantitativa em Administração. São Paulo: Atlas, 2009.

CAVALCANTE, Anderson. O que realmente Importa? Rio de Janeiro: Sextante, 2012.

CENTRO UNIVERSITÁRIO UNIVATES. Manual do curso de Administração - linha de formação específica em administração de empresas. 2014. Lajeado/RS. Disponível em: <http://www.univates.br/files/files/univates/graduacao/manuais_cursos/Manual_LFE_ Administracao_Empresas.pdf>. Acesso em: 06 set. 2014.

CHEMIN, Beatris Francisca. Manual da Univates para trabalhos acadêmicos: planejamento, elaboração e apresentação. Lajeado: Ed. da Univates, 2012.

CHIAVENATO, Idalberto. Administração de Recursos Humanos: fundamentos básicos. 7. ed. Barueri, SP: Manole, 2009.

CHIAVENATO, Idalberto. Carreira: você é aquilo que faz. São Paulo: Saraiva, 2006.

CHIAVENATO, Idalberto. Introdução à teoria geral da Administração. 6. ed. Rio de Janeiro: Campus, 2000.

COSTA, Luciano Venelli. Conciliação de expectativas de carreira entre as pessoas e as organizações. In: DUTRA, Joel Souza. Gestão de careiras na empresa contemporânea. São Paulo: Atlas, 2010, p.133-154.

DUTRA, Joel Souza. Administração de Carreiras: uma proposta para repensar a gestão de pessoas.1. ed. 12. reimpr. São Paulo: Atlas, 2011.

GIL, Antônio C. Como elaborar projetos de pesquisa. 4. ed. São Paulo: Atlas, 2007.

GIL, Antonio C. Gestão de Pessoas: enfoque nos papéis profissionais. São Paulo: Atlas, 2009.

LAKATOS, E. M.; MARCONI, M. de A. Fundamentos de metodologia científica. 7. ed. São Paulo: Atlas, 2010.

LANCASTER, Lynne C.; STILLMAN, David. O Y da questão - Como a geração Y está transformando o mercado de trabalho. São Paulo: Saraiva, 2011.

MALHOTRA, Naresh K. Pesquisa de marketing: uma orientação aplicada. 4. ed. São Paulo: Bookman, 2004.

MARQUES, José Roberto; CARLI, Edson. Coaching de carreira: Construindo profissionais de sucesso, São Paulo: Ser Mais, 2012.

MOTTA, Paulo Roberto. Reflexões sobre a Customização das Carreiras Gerenciais: a Individualidade e a Competitividade contemporâneas. In: BALASSIANO, Moisés; COSTA, Isabel de Sá A. Gestão de carreiras: dilemas e perspectivas. São Paulo: Atlas, 2012.p.9-19.

NASCIMENTO, Luiz Paulo do; CARVALHO, Antônio Vieira de. Gestão estratégica de pessoas. Sistema, remuneração e planejamento. Rio de Janeiro: Qualitymark, 2006.

OLIVEIRA, Djalma de Pinho Rebouças. Plano de carreira: foco no indivíduo. São Paulo: Atlas, 2009.

OLIVEIRA, Sidnei. Geração Y: o nascimento de uma nova versão de líderes. São Paulo: Integrare Editora, 2010.

OSBORN, Richard N.; HUNT, James G. e SCHERMERHORN Jr., John R. Fundamentos do Comportamento Organizacional. 2. ed. São Paulo: Bookman,1998. 
PASCHOAL, Jose Wilson Armani. A arte de gerir pessoas em ambientes criativos. Rio de Janeiro: Record, 2004.

PASSOS, Alfredo; NAJJAR, Eduardo Rienzo. Carreira e Marketing Pessoal. São Paulo: Negócio Editora, 1999. 2006.

RICCI, Renato. O que é coaching e como ele pode transformar você? São Paulo: Qualitec,

ROBBINS, Stephen P. Comportamento organizacional. São Paulo: Person Prentice Hall, 2005.

ROBBINS, Stephen P. Fundamentos do Comportamento Organizacional. 8. ed. São Paulo: Pearson Prentice Hall, 2009.

SÁ, Patrícia Freitas de. Carreiras e a nova geração produtiva: Quais as expectativas de carreira de jovens profissionais? Pontifícia Universidade Católica do Rio de Janeiro. Rio de Janeiro: Departamento de Administração, 2011.

TOLFO, Suzana da Rosa. A carreira profissional e seus movimentos: revendo conceitos e formas de gestão em tempos de mudanças.In: Rev. Psicol. Organ. Trab., Florianópolis, v. 2, n. 2, dez. 2002. Disponível em: <http://pepsic.bvsalud.org/scielo.php?script=sci_ arttext\&pid=S1984-66572002000200003\&lng=pt\&nrm=iso>. Acesso em: 12 out. 2014.

VERGARA, Sylvia Constant. Projetos e relatórios de pesquisa em administração. 12. ed. São Paulo: Atlas,2010.

XAVIER, Ricardo de Almeida Prado. Sua Carreira: planejamento e gestão:como desenvolver melhor seus talentos e competências. São Paulo: Prentice Hall, 2006. 